\title{
Associations of sport participation with self- perception, exercise self-efficacy and quality of life among children and adolescents with a physical disability or chronic disease-a cross-sectional study
}

Saskia J. te Velde ${ }^{1 *}$, Kristel Lankhorst ${ }^{1}$, Maremka Zwinkels ${ }^{2}$, Olaf Verschuren ${ }^{2}$, Tim Takken ${ }^{3+}$, Janke de Groot ${ }^{1,2,4 \dagger}$ on behalf of the HAYS study group

\begin{abstract}
Background: Little evidence is available about how sports participation influences psychosocial health and quality of life in children and adolescents with a disability or chronic disease. Therefore, the aim of the current study is to assess the association of sports participation with psychosocial health and with quality of life, among children and adolescents with a disability.

Methods: In a cross-sectional study, 195 children and adolescents with physical disabilities or chronic diseases (11\% cardiovascular, 5\% pulmonary, 8\% metabolic, 8\% musculoskeletal/orthopaedic, 52\% neuromuscular and 9\% immunological diseases and 1\% with cancer), aged 10-19 years, completed questionnaires to assess sports participation, health-related quality of life (DCGM-37), self-perceptions and global self-worth (SPPC or SPPA) and exercise self-efficacy.

Results: Regression analyses showed that those who reported to participate in sports at least twice a week had more beneficial scores on the various indicators compared to their peers who did not participate in sport or less than twice a week. Those participating in sports scored better on all scales of the DCGM-37 scale, on the scales for feelings of athletic competence and children but not adolescents participating in sports reported greater social acceptance. Finally, we found a strong association between sport participation and exercise self-efficacy.

Conclusions: This study provides the first indications that participating in sports is beneficial for psychosocial health among children and adolescents with a disability. However, more insight is needed in the direction of the relationships.
\end{abstract}

Keywords: Sport, Disability, Psychosocial, Quality of life

\footnotetext{
* Correspondence: saskia@tevelderesearch.com

${ }^{\dagger}$ Tim Takken and Janke de Groot contributed equally to this work.

${ }^{1}$ University of Applied Sciences, Utrecht, the Netherlands

Full list of author information is available at the end of the article
} 


\section{Key points}

- Children and adolescents with a physical disability or chronic disease who are participating in sports scored better on all scales of the DCGM-37 scale reflecting a better health-related quality of life

- Participating in sports was associated with feelings of athletic competence in children and adolescents with a disability or chronic disease. In addition, children, but not adolescents, participating in sports reported higher feelings of social acceptance.

- Sport participation among children and adolescents with a physical disability or chronic disease was strongly positively associated with exercise self-efficacy.

\section{Background}

Physical activity and sports participation have several health benefits for people of all ages [1]. Engaging in sufficient levels of physical activity improves cardiopulmonary health, strength, flexibility and endurance, and has been related to reduce risks for cardiovascular diseases and specific cancers [2,3]. Moreover, physical activity, especially sports, exercise and leisure time activities, has been related to reductions in mortality [4]. In addition, due to its social nature, sports participation provides opportunities for social interaction, companionship and may therefore have greater benefits for social and mental well-being than other domains of physical activity [5-8]. Furthermore, sports participation may enhance health-related quality of life in adults as well as in children and adolescents $[9,10]$. Health-related quality of life is a broadly defined construct evaluating the health status from the person's perspective covering physical, emotional, mental, social and functional domains [11] and has been used in evaluations of sport and exercise interventions (e.g. $[12,13])$.

The benefits of sport and physical activity for psychosocial health, i.e. one's mental processes, self-reflections and interactions with others, are universal and not restricted to healthy adults and typically developing children and adolescents. In the contrary, children and adolescents with a chronic disease or physical disability (CDPD) may benefit even more [14]. Both children with a physical disability as well as children with a chronic disease may experience similar barriers for sport participation. They both have lower fitness levels, lower levels of physical activity and a higher prevalence of overweight and obesity [15-17]. Sport and physical activity does not only improve the physical functioning and physical independence in both groups, but also it may enhance inclusion and well-being. For example, a review about leisure time activities and quality of life among children and adolescents with neurological disabilities reported that participation in active leisure time activities was associated with better physical well-being, improved sense of self, emotional well-being and promote social well-being [18]. Unfortunately, children and adolescents with CDPD engage less often in physical activities and sports [17, 19, 20]. Furthermore, these children and adolescents may experience low levels of self-worth and quality of life due to their physical limitations and body image concerns [21-24]. Therefore, insight in the potential beneficial effects of physical activity and in particular sports participation, as a specific sub-domain of physical activity, is important for subsequent interventions promoting sports participation among children and adolescents with disabilities.

So far, only a few studies addressed the association of sports participation with psychosocial health and quality of life in children and adolescents in general or in children and adolescents with CDPD. Dinomais and colleagues [25] showed that young people with disabilities who participated in competitive sports scored high on social functioning, which is in line with the review by Sahlin and Lexel [9] who concluded that children and adolescents with a disability who engaged in sports reported similar scores on self-concept than non-disabled athletes. However, it remains unclear whether positive associations were the result of the physical activity itself, or of the social interaction and learning environment of the sports club. A study among 15-69 year-old French men and women showed that across all levels of physical activity, sports participation was positively associated with quality of life [26]. In addition, the review by Eime and colleagues [5] reported that club- and team-based sports participation resulted in better psychosocial health outcomes than individual forms of sports.

The aforementioned studies used different indicators, each measuring different but related aspects of psychosocial health. Positive self-worth, self-perceptions, self-esteem, social support and self-efficacy are acknowledged indicators of psychosocial health and quality of life [23, 27]. Involvement in sports, and the interaction with others in this context, allows children and adolescents to develop their self-concept, especially related to the physical and social domains [28]. A systematic review found that physical activity was strongly associated with perceived (athletic) competence [29]. A meta-analysis supported the proposition that physical activity positively influences body image, and this effect was larger in adolescents compared to students, adults and older adults [30]. In summary, participation in physical activity may have an impact on many aspects of psychosocial health; however, the evidence available about how sports participation influences psychosocial health and quality of life in children and adolescents with a disability is still scarce. Therefore, the aim of the current study is to assess the association of sports participation with psychosocial 
health, specifically, self-perceptions, exercise self-efficacy and quality of life, among children and adolescents with a disability. Based on previous studies, we hypothesise that children and adolescents who participate in sport have more favourable scores on these indicators of psychosocial health and quality of life.

\section{Methods}

\section{Design and sample}

Cross-sectional data from two related studies using identical outcomes were combined. Firstly, the cross sectional Health in Adapted Youth Sports (HAYS) study that includes children and adolescents aged 10-19 years old with a chronic disease or physical disability (CDPD) [31]. Secondly, the baseline data from the Sports-2-Stay Fit (S2SF) study which is a clinically controlled trial among children and adolescents aged 6-19 years with a CDPD [32].

For both studies, children and adolescents were recruited through patient organisations, paediatric physical therapy practices, Wilhelmina Children's Hospital in Utrecht, De Hoogstraat Rehabilitation Center, Fitkids and schools (for special education) in the Netherlands.

Inclusion criteria were having a physical disability or a chronic disease (cardiovascular, pulmonary, musculoskeletal or neuromuscular disorder), aged between 10 and 19 years (HAYS) or between 6 and 19 years (S2SF), ability to understand simple instructions, able to perform physical fitness tests. Children and adolescents were not eligible for participation in these studies if they had a progressive disease, used an electric wheelchair, participated in other (research) projects that may influence the results of the current studies, or did not sign the informed consent form.

For the current study, children and adolescents were included in the analyses if they had valid data on sports participation and valid data on at least one of the outcome variables (quality of life, self-efficacy, self-perceptions, general self-worth). Eight children and adolescents from the S2SF-study did not complete the online questionnaires during their first assessment, but did during the second assessment (8 weeks later). For that reason, we included data from these eight children or adolescents from their second assessment. We assumed that even though their scores may have been improved in that 8-week period, this will not affect the association between sports participation and these variables.

In total, 197 participants had complete data on sports participation, of whom two had no valid data on the outcome variables. Of the remaining 195 participants, 177 participants had complete data on all outcome variables, another 13 participants had valid data on two of the three outcome variables and 5 participants had valid data on only one outcome variables. The distribution of valid data on the outcome variables did not differ by sport participation status $(p=0.428)$ or by diagnosis (ACSM category) ( $p=0.346)$ or by gender $(p=0.393)$. We included 195 children and adolescents who had complete data on sports participation and at least one outcome variable. Of those included children and adolescents, 145 participated in the HAYS study, while 50 participated in the S2SF study.

\section{Procedures}

The procedures and protocols for the HAYS and the S2SF study have been described elsewhere in more detail [31, 32]. Briefly, participants who agreed to participate and met the inclusion criteria were scheduled for an assessment at the lab (University of Applied Science, Utrecht). 1 week before this visit to the laboratory, the participants or their parents received a secured link to online questionnaires assessing exercise self-efficacy and quality of life. These questionnaires took about 10-15 min to complete. When the children visited the laboratory, they were first asked to complete the questionnaires on self-perceptions and global self-worth in the presence of one of the researchers or research assistants, which took about $10 \mathrm{~min}$. When they finished the questionnaires their physical fitness, cognition and cardiovascular health was assessed, which took on average about $2 \mathrm{~h}[31,32]$.

The studies were approved by the Medical Ethics Committee of the University Medical Center Utrecht, the Netherlands. (METC number: 14-332/c and 14-118/m). All participants and the parents of participants under 18 years of age provided their informed written consent. Studies were conducted in accordance with the Helsinki Declaration.

\section{Measurements \\ Independent variable}

Sports participation Sports participation was assessed by means of a questionnaire that was completed before the start of the physical fitness tests. Sports participation was identified using three standardised questions used by the National Institute for Public Health and the Environment (RIVM) [33] (1) "do you participate in organized sports?" (2) "what is/are the type of organized sport(s)?" and (3) "what is the frequency of participation in organized sports per week?". When participants indicated that they participate in organised sports at least two times per week, they were classified as 'participating in sports', all others were classified as 'non-sporting'. This cut-off was based on the Consensus statement for the Dutch Guidelines for Physical Activity for youth ( $<18$ years old) [34]. This guideline was developed for typically developing children and was in place at the time of the start of the current research project. It advises that children and adolescents should be physically active for at least $1 \mathrm{~h}$ per day at at least a moderate intensity. In addition, children and adolescents should engage 
in activities that specifically address physical fitness at least two times a week. Sport activities are typically activities in which physical fitness, including strength, flexibility and coordination, are addressed. However, there are no universally accepted guidelines for children and adolescents with a chronic disease of physical disability and Van Brussel and colleagues [35] advise to use a training frequency of minimally two times per week. This is in line with recommendations for people with cerebral palsy that were based on a comprehensive literature review, expert opinions and extensive clinical experience [36].

\section{Dependent variables}

Health-related quality of life To evaluate the quality of life, the Dutch version of the Disabkids (DCGM-37) was used, which was completed online by either the participant alone $(n=45)$, together with one of the parents/caregivers $(n=54)$ or the parent alone $(n=9)$ (unknown for $n=89$ ). This questionnaire measures the quality of life and the independence of children and adolescents with chronic health conditions. The questionnaire has been used in other paediatric populations and has been tested for internal consistency and validity [37-39] The questionnaire includes 37 items that cover six subscales, i.e. mental independence, mental emotion (inner strength), social inclusion, social exclusion (social equality), physical limitations (physical ability) and physical treatment (i.e. the impact of taking medication, receiving injections, etc.) [38]. All items were scored on a 5-point Likert scale ranging from 1 = never to 5 = always. For each scale, a sum score was calculated by following the instructions of the developers of the DCGM-37 and the provided syntax file [38]. If one item was missing, this missing value was substituted by the mean of the non-missing values. If more than 1 item of a domain was missing, no sum score was calculated. These scores were transformed so that they had a range from 0 to 100 with higher scores indicating a higher perceived quality of life.

Self-perception and global self-worth To evaluate selfperception, the Dutch translations of the self-perception profile for children (SPPC) and for adolescents (SPPA) were used [40]. We used the children's version for children of 12 years old and younger, or with cognitive capabilities of this age group, and the adolescent version for those older than 12 years. Based on the researcher's expertise, an older child was provided the children's version or when the child clearly was not able to complete the adolescent version or did not understand the questions. The children's version uses 36 items to measure five domains, i.e. 'scholastic competence, 'social acceptance', 'athletic competence,' 'physical appearance,' 'Behavioural conduct', and the general concept 'global self-worth'
$[41,42]$. All six scales consist of 6 items that include bipolar statements (e.g. 'some kids feel they are very good at school, but other kids worry about whether they do the schoolwork assigned to them'). The children have to choose which of the two statements resembles them, and how much, i.e. 'sort of true for me' or 'really true for me'. All items were scored on a 4-point scale and sum scores were calculated. The questionnaire has been tested in a Dutch norm group and showed reasonable to good internal consistency and test-retest reliability [42].

The adolescent version includes 35 items which make up 7 scales, i.e. 'scholastic competence,' social acceptance,' 'athletic competence,' 'physical appearance', 'behavioural conduct,' 'close friendship' and the general concept 'global self-worth'. Similar to the child version of the questionnaire, all items included bipolar statements that were scored on a 4-point scale by which the adolescents indicated which statement resembled them 'sort of true' or 'really true' [43].

If one item of the scale was missing, the scale score was not calculated $(n=3)$. All scores on each scale were compared to Dutch norm scores to indicate whether the participants scored 'below average', i.e. below the 15th percentile, or above average, i.e. at or higher than the 85th percentile. For the child version, different norms have been formulated for boys and girls [41]. For the adolescent version, different norms were formulated by school level for the scales 'scholastic competence' and 'behavioural conduct' and a distinction by sex was made for all scales except 'social acceptance' [43]. In the current study, results regarding these norm scores were only used for descriptive purposes.

Exercise self-efficacy To assess whether sport participation was associated with exercise self-efficacy, the Dutch version of the Exercise Self-Efficacy Scale [44, 45] was filled out digitally at home by the child. Self-efficacy is a well-known behavioural determinant and described in several behavioural theories such as the Social Cognitive Theory by Bandura [46] in which self-efficacy is seen as important influencer of behaviour. In the current study, we hypothesise that behaviour, in this study engaging in sport, can have a positive impact on self-efficacy in relation to physical activity and exercise. This hypothesis is based on the fact that mastery experiences and vicarious experiences are important sources of self-efficacy [47] and when participating in sport, children may learn new skills and may see others like themselves performing specific tasks or behaviours. The questionnaire takes approximately $2 \mathrm{~min}$ to complete. The questionnaire consists of 10 items about the level of self-confidence with regard to performing regular physical activities and exercise that could be rated on a 4-point Likert scale ranging from 'not true at all' to 'always'. A sample item 
is "I am confident that I can overcome barriers and challenges with regard to physical activity and exercise if I try hard enough". A sum score was calculated when all 10 items were answered. Internal consistency of the scale was high, Cronbach's alpha $=0.99$. A higher score indicates a higher exercise self-efficacy. Validity and reliability of the scale have been tested in a sample with spinal cord injury and showed good validity and adequate reliability [44].

\section{Potential confounders and co-variates}

Demographic variables The demographic questionnaire that included questions about date of birth, sex and school level.

Medical diagnosis The general questionnaire assessed the medical diagnosis. The medical diagnoses were further classified in categories according to The American College of Sports Medicine (ACSM) [48]: 1. Cardiovascular (e.g. ventricular septal defect, tetralogy of Fallot, cardiomyopathy), 2. Pulmonary (asthma), 3. Metabolic (diabetes), 4. Musculoskeletal or orthopaedic (amputation, clubfoot, hereditary multiple exostoses-multiple osteochondromas, congenital anomalies), 5. Neuromuscular (cerebral palsy, spina bifida, neurofibromatosis, Kabubi syndrome, centronuclear myopathy, psychomotor retardation, Martsolf syndrome, acquired brain injury), 6. Immunological or haematological (rheumatism, Fanconi anaemia), 7. Cancer (tumour in hypophysis), 8. Epilepsy. In the regression analyses, categories were merged distinguishing disabilities or disease related to the metabolic system or oxygen transport (1. Cardiovascular, 2 Pulmonary, and 3. Metabolic) from the other disabilities or diseases, mostly related to the musculoskeletal or neurological system.

School type Children participating in the current study attended either regular education or special education for children with physical disabilities (so called mytyl schools). These schools, dedicated to children with CDPD, have similar learning objectives as regular schools, but the children receive additional attention and support. Children attending special education may have different references for social comparison which may influence how they perceive themselves. Therefore, school type was added as a potential confounder in the analyses.

\section{Statistical analyses}

Continuous data was described by means or medians and standard deviations or interquartile ranges and categorical data by frequencies and proportions. Crude comparisons on the outcome variables between the sporting and nonsporting participants were made using ANOVA. Adjusted associations between sports participation and the outcome variables were estimated by linear (or logistic) regression analyses. Assumptions were checked, and residuals showed an acceptable normal distribution, except for the Exercise Self-Efficacy scale. Therefore, the scale was dichotomized at the third tertile (score $\geq 37$ ) and associations with sports participation were assessed by means of logistic regression analyses. Sensitivity analyses were run with and without outliers, i.e. those with standardised residual scores below -3 or higher than 3 .

Different models will be presented, unadjusted as well as adjusted for potential confounders' sex, age, school type, diagnosis or ACSM category. All analyses were checked for potential interaction by age. In case of significant interactions, results will be presented for two age groups. For the analyses, the ACSM categories were merged into two categories, i.e. one including those with cardiovascular, pulmonary and metabolic conditions, and another including those with musculoskeletal, neuromuscular, immunological, cancer or epileptic conditions. Results are reported as regression coefficients or odds rations and their 95\% confidence intervals.

\section{Results}

Of the 195 children included in the current study, 96 were classified as participating in sports (see Table 1 ). Based on the ACSM classification, most children $(n=104$ $(52.8 \%))$ had a neuromuscular condition (Table 1), followed by cardiovascular disease $(n=22(11.3 \%))$. One third of the children attended special education.

Table 1 Characteristics of the study sample $(N=195)$

\begin{tabular}{|c|c|c|}
\hline & Mean & Standard deviation \\
\hline \multirow[t]{2}{*}{ Age (years) } & 14.3 & 2.8 \\
\hline & $\mathrm{n}$ & $\%$ \\
\hline Study ${ }^{1}$ (HAYS) & 145 & 74.4 \\
\hline Sex (boys) & 116 & 59.5 \\
\hline Sport participation ${ }^{2}$ (yes) & 96 & 49.2 \\
\hline \multicolumn{3}{|l|}{ ACSM } \\
\hline Cardiovascular & 22 & 11.3 \\
\hline Pulmonary & 9 & 4.6 \\
\hline Metabolic & 16 & 8.2 \\
\hline Musculoskeletal or orthopaedic & 16 & 8.2 \\
\hline Neuromuscular & 103 & 52.8 \\
\hline Immunological or haematological & 18 & 9.2 \\
\hline Cancer & 3 & 1.5 \\
\hline Epileptic & 8 & 4.1 \\
\hline \multicolumn{3}{|l|}{ Education type $^{3}$} \\
\hline Special-education & 65 & 33.3 \\
\hline
\end{tabular}

${ }^{1}$ Participating in either the HAYS or the S2SF study

${ }^{2}$ Sport participation is defined here as participating in sport at least two times a week

${ }^{3}$ Education type could be regular education or special education 
Table 2 shows the descriptive statistics regarding the outcome variables. The mean scores on the different subscales for the DCGM-37 varied, it was lowest for the social exclusion scale $(62.9(17.7))$ and highest for the mental emotion (77.9 (17.8)) and physical treatment (77.1 (22.1)). When looking at the norm scores for the SPPC and SPPA, a relatively high proportion of children scores below the norm for social acceptance (SPPA, 21.3\%) and athletic competence (SPPC, 25\%; SPPA, 23.45). On the other hand, relatively many children score above the 85th percentile for scholastic competence (SPPA, 29.2\%), social acceptance (SPPC, 25.7\%), athletic competence (SPPC, 23.6\%) and behavioural conduct (SPPC, 35.0\%; SPPA, 33.3\%).

Table 3 displays the unadjusted comparisons on the outcome variables between sporting and non-sporting participants. Those participating in sports scored higher on all subscales of the DCGM-37, except on the physical treatment scale. The significant differences in the unadjusted analyses remained statistically significant after adjustment for potential confounders, indicating that school type and medical diagnosis did not substantially confound the association (Table 4).

Children participating in sports reported higher scores on social acceptance and athletic competence than their non-sporting peers, while no differences were observed for the other scales of the SPPC (Table 3). These differences became slightly stronger after adjustment for potential confounders (Table 4).

The adolescents who participated in sports, scored higher on athletic competence than the non-sporting adolescents (SPPA, Table 3). Moreover, this difference became slightly larger after adjustment of age, gender, school type and ACSM classification (Table 4). In addition,

Table 2 Descriptive statistics for quality of life, self-perceptions, global self-worth and self-efficacy

\begin{tabular}{|c|c|c|c|c|c|c|c|c|}
\hline$\overline{\text { DISABKIDS (DCGM-37) }}$ & $N$ & Mean & SD & Median & $\mathrm{p}_{25}$ & $\mathrm{p}_{75}$ & Min & Max \\
\hline Mental independence (range 0-100) & 187 & 75.8 & 14.6 & 79.2 & 66.7 & 87.5 & 33.3 & 100 \\
\hline Mental emotion (range 0-100) & 187 & 77.9 & 17.8 & 78.6 & 67.9 & 92.9 & 28.6 & 100 \\
\hline Social inclusion (range 0-100) & 187 & 62.9 & 17.7 & 66.7 & 50.0 & 75.0 & 16.7 & 100 \\
\hline Social exclusion (range 0-100) & 187 & 75.8 & 17.9 & 79.2 & 66.7 & 91.7 & 12.5 & 100 \\
\hline Physical limitations (range 0-100) & 187 & 68.0 & 18.5 & 70.8 & 54.2 & 83.3 & 12.5 & 100.0 \\
\hline Physical treatment (range 0-100) & 87 & 77.1 & 22.1 & 83.3 & 66.7 & 91.7 & 20.8 & 100 \\
\hline General (31 items) (range 0-100) & 187 & 72.3 & 1.5 & 72.6 & 61.3 & 83.9 & 29.0 & 100 \\
\hline Self-perception profile for children (SPPC) & N & Mean & SD & Median & $p_{25}$ & $p_{75}$ & $\%<\mathrm{p}_{15}{ }^{2}$ & $\%>p_{85}{ }^{3}$ \\
\hline Scholastic competence (6 items, range 6-24) & 140 & 17.1 & 4.0 & 17 & 14 & 20 & 16.4 & 18.6 \\
\hline Social acceptance (6 items, range 6-24) & 140 & 18.2 & 4.2 & 18 & 16 & 22 & 15.0 & 25.7 \\
\hline Athletic competence (6 items, range 6-24) & 140 & 17.6 & 4.4 & 18 & 15 & 21 & 25.0 & 23.6 \\
\hline Physical appearance (6 items, range 6-24) & 140 & 19.3 & 4.4 & 20 & 17 & 23 & 15.7 & 19.3 \\
\hline Behavioural conduct (6 items, range 6-24) & 140 & 18.8 & 3.8 & 19 & 17 & 22 & 11.4 & 35.0 \\
\hline Global self-worth (6 items, range 6-24) & 139 & 20.2 & 3.3 & 21 & 18 & 23 & 13.7 & 22.3 \\
\hline Self-perception profile for adolescents (SPPA) & N & Mean & SD & Median & $\mathrm{p}_{25}$ & $\mathrm{p}_{75}$ & $\%<\mathrm{p}_{15}$ & $\%>p_{85}$ \\
\hline Scholastic competence (5 items, range 5-20) & 48 & 14.8 & 2.9 & 15 & 13 & 17 & 14.6 & 29.2 \\
\hline Social acceptance (5 items, range $5-20$ ) & 47 & 14.8 & 2.9 & 15 & 13 & 17 & 21.3 & 6.4 \\
\hline Athletic competence (5 items, range 5-20) & 47 & 13.1 & 4.0 & 14 & 10 & 16 & 23.4 & 14.9 \\
\hline Physical appearance (5 items, range 5-20) & 47 & 14.0 & 3.2 & 14 & 12 & 16 & 12.8 & 10.6 \\
\hline Behavioural conduct (5 items, range 5-20) & 48 & 15.9 & 2.9 & 16 & 15 & 18 & 4.2 & 33.3 \\
\hline Close friendship (5 items, range $5-20$ ) & 47 & 17.6 & 2.2 & 18 & 17 & 19 & 4.2 & 10.4 \\
\hline \multirow[t]{2}{*}{ Global self-worth (5 items, range 5-20) } & 46 & 15.7 & 2.7 & 16 & 14 & 18 & 10.9 & 10.9 \\
\hline & $\mathrm{N}$ & Mean & SD & Median & $\mathrm{p}_{25}$ & $\mathrm{p}_{75}$ & Min & Max \\
\hline \multirow[t]{2}{*}{ Exercise self-efficacy (sum score 10 items) } & 187 & 33.8 & 5.3 & 35 & 31 & 38 & 14 & 40 \\
\hline & & $n$ & $\%$ & & & & & \\
\hline Exercise self-efficacy (dichotomized, $>$ third tertile) & 187 & 71.0 & 38.0 & & & & & \\
\hline
\end{tabular}

${ }^{1}$ All subscales are scored from 0 to 100 with higher scores indicating higher self-perceived health-related quality of life; $p_{25}-25$ th percentile; $p_{75}-75$ th percentile ${ }^{2}<\mathrm{p}_{15}$ based on a reference sample

${ }^{3}>p_{85}$ base on a reference sample 
Table 3 Unadjusted comparisons on quality of life, self-perceptions, global self-worth and self-efficacy between sporting and non-sporting participants

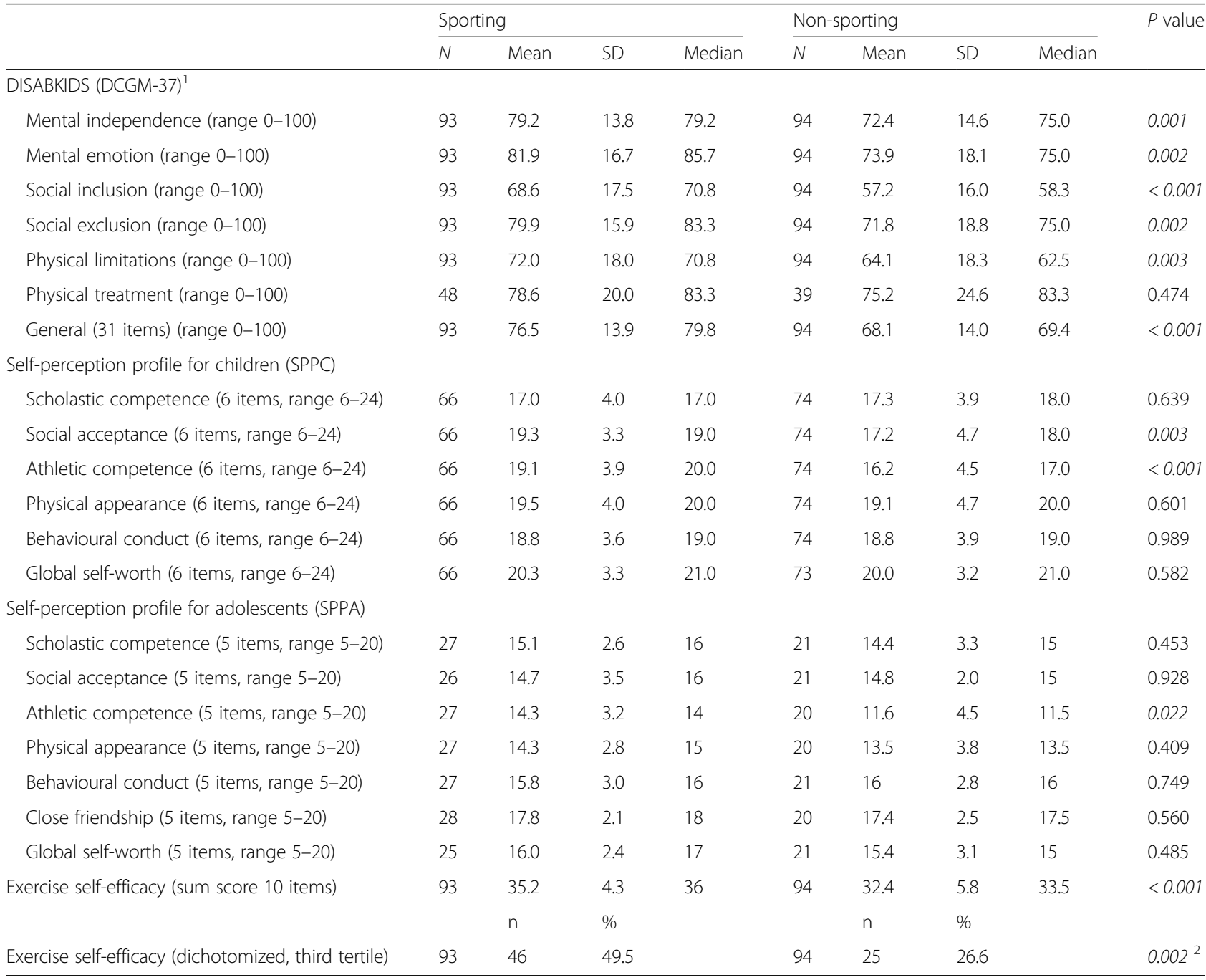

Italicize data indicate statistical significance

${ }^{1}$ All subscales are scored from 0 to 100 with higher scores indicating higher self-perceived health-related quality of life

${ }^{2}$ Tested with a chi-square test

after adjustment for potential confounders, the scores on the scale for close friendships was significantly higher for adolescents participating in sports compared to their nonsporting peers.

Those participating in sports scored more often in the upper tertile on the exercise self-efficacy scale than their non-sporting peers (Tables 3 and 4). After adjustment for school type and medical diagnosis, the odds ratio decreased slightly, but remained significant. Those who participate in sports were 2.55 more likely to score in the upper tertile for exercise self-efficacy, independent of sex, school type or medical diagnosis (Table 4).

\section{Discussion}

The current study aimed to assess the associations between sports participation and psychosocial health among children and adolescents with a disability. In general, those who reported to participate in sports at least twice a week, had more beneficial scores on the various indicators compared to their peers who did not participate in sports or less than twice a week. This was independent of age, sex, school type or medical diagnosis and largely in line with our hypotheses.

Those participating in sports scored better on all scales of the DCGM-37 scale. The effect sizes were quite substantial, for the total score the difference between the groups was about 7 points. Although the fact that the DCGM-37 distinguishes six sub-scales reflecting different concepts, these sub-scales were strongly correlated in the current sample. Therefore, it is not surprising that the groups differed on all sub-scales. Unfortunately, it is difficult to compare these findings with other studies, due to 
Table 4 Results from regression analyses comparing sporting (1) and non-sporting participants (0) on health-related quality of life, self-perceptions, global self-worth and exercise self-efficacy

\begin{tabular}{|c|c|c|c|c|c|c|}
\hline & \multicolumn{2}{|c|}{ Model $1^{\text {a }}$} & \multicolumn{2}{|c|}{ Model $2^{b}$} & \multicolumn{2}{|c|}{ Model $3^{c}$} \\
\hline & $b$ & $95 \% \mathrm{Cl}$ & $b$ & $95 \% \mathrm{Cl}$ & $\bar{b}$ & $95 \% \mathrm{Cl}$ \\
\hline \multicolumn{7}{|l|}{ DISABKIDS (DCGM-37) } \\
\hline Mental independence (range 0-100) & 6.06 & $(1.83 ; 10.3)$ & 4.68 & $(0.18 ; 9.18)$ & 5.75 & $(1.41 ; 10.1)$ \\
\hline Mental emotion (range 0-100) & 6.32 & $(1.19 ; 11.5)$ & 6.24 & $(0.74 ; 11.7)$ & 7.06 & $(1.60 ; 12.5)$ \\
\hline Social inclusion (range 0-100) & 11.0 & $(5.99 ; 16.0)$ & 7.76 & $(2.56 ; 13.0)$ & 8.86 & $(3.80 ; 13.9)$ \\
\hline Social inclusion (range 0-100) & 7.56 & $(2.35 ; 12.8)$ & 5.63 & $(0.11 ; 11.1)$ & 6.79 & $(1.42 ; 12.2)$ \\
\hline Physical limitations (range $0-100$ ) & 6.75 & $(1.35 ; 12.1)$ & 5.82 & $(0.05 ; 11.6)$ & 7.02 & $(1.39 ; 12.6)$ \\
\hline Physical limitations (range $0-100$ ) & n.a. & & n.a. & & n.a. & \\
\hline General (31 items) (range 0 - 100) & 7.50 & $(3.35 ; 11.7)$ & 6.03 & $(1.63 ; 10.4)$ & 7.09 & $(2.86 ; 11.3)$ \\
\hline \multicolumn{7}{|l|}{ Self-perception profile for children (SPPC) } \\
\hline Scholastic competence (6 items, range 6-24) & -0.86 & $(-2.17 ; 0.45$ & -0.36 & $(-1.76 ; 1.03$ & -0.42 & $(-1.81 ; 0.96$ \\
\hline Social acceptance (6 items, range 6-24) & 1.63 & $(0.26 ; 3.01)$ & 2.00 & $(0.52 ; 3.48)$ & 2.01 & $(0.52 ; 3.50)$ \\
\hline Athletic competence (6 items, range 6-24) & 1.90 & $(0.49 ; 3.31)$ & 2.69 & $(1.21 ; 4.17)$ & 2.65 & $(1.17 ; 4.12)$ \\
\hline Physical appearance (6 items, range 6-24) & -0.50 & $(-1.95 ; 0.94)$ & -0.23 & $(-1.79 ; 1.33)$ & -0.26 & $(-1.82 ; 1.31$ \\
\hline Behavioural conduct (6 items, range 6-24) & 0.25 & $(-0.87 ; 1.38)$ & 0.48 & $(-0.74 ; 1.69)$ & 0.48 & $(-0.74 ; 1.70)$ \\
\hline Global self-worth (6 items, range 6-24) & 0.15 & $(-0.93 ; 1.23)$ & 0.50 & $(-0.65 ; 1.66)$ & 0.47 & $(-0.68 ; 1.63)$ \\
\hline \multicolumn{7}{|l|}{ Self-perception profile for adolescents (SPPA) } \\
\hline Scholastic competence (5 items, range 5-20) & 0.623 & $(-1.249 ; 2.496)$ & 0.504 & $(-1.393 ; 2.401)$ & 0.849 & $(-1.242 ; 2.940)$ \\
\hline Social acceptance (5 items, range $5-20$ ) & 0.058 & $(-1.856 ; 1.973$ & 0.112 & $(-1.844 ; 2.067)$ & 1.173 & $(-0.925 ; 3.270)$ \\
\hline Athletic competence (5 items, range 5-20) & 2.385 & $(-0.075 ; 4.845)$ & 2.542 & $(0.043 ; 5.041)$ & 3.319 & $(0.647 ; 5.992)$ \\
\hline Physical appearance (5 items, range $5-20$ ) & -0.013 & $(-2.029 ; 2.004)$ & -0.132 & $(-2.183 ; 1.919)$ & -0.030 & $(-2.283 ; 2.222)$ \\
\hline Behavioural conduct (5 items, range 5-20) & -0.241 & $(-1.791 ; 1.309)$ & -0.401 & $(-1.946 ; 1.144)$ & -0.181 & $(-1.881 ; 1.520)$ \\
\hline Close friendship (5 items, range 5-20) & 0.849 & $(-0.592 ; 2.289)$ & 0.676 & $(-0.755 ; 2.108)$ & 1.636 & $(0.269 ; 3.002)$ \\
\hline \multirow[t]{2}{*}{ Global self-worth (5 items, range $5-20$ ) } & -0.666 & $(-2.545 ; 1.213)$ & -0.832 & $(-2.723 ; 1.059)$ & -0.360 & $(-2.473 ; 1.753)$ \\
\hline & OR & $95 \% \mathrm{Cl}$ & OR & $95 \% \mathrm{Cl}$ & OR & $95 \% \mathrm{Cl}$ \\
\hline Exercise self-efficacy (dichotomized, third tertile) & 2.72 & $(1.47 ; 5.02)$ & 2.24 & $(1.17 ; 4.27)$ & 2.55 & $(1.30 ; 4.99)$ \\
\hline
\end{tabular}

Italicize data indicate statistical significance



${ }^{b}$ Further adjusted for school type

${ }^{\mathrm{C}}$ Further adjusted for ACSM classification (recoded into two categories (cardiovascular, pulmonary, metabolic impairments vs musculoskeletal, neuromuscular, immunological, cancer, epileptic impairments/diseases)

$b$, regression coefficient, reflects the difference in score between non-sporting (0) and sporting (1) children; $95 \% \mathrm{Cl}, 95 \%$ confidence interval; $n . a .$, not applicable, too few children who completed this scale

the fact that other instruments to assess quality of life were used, or that other studies did not made comparisons between sporting and non-sporting participants. However, our findings support the hypothesis that participating in organised sports by children and adolescents with a CDPD can contribute to all domains of quality of life and are in line with two studies among adults $[49,50]$.

Furthermore, our findings regarding the self-perceptions are in line with the existing reviews among adults, children and adolescents $[29,30]$, and show that participating in organised sports contributes to feelings of athletic competence in children and adolescents with a CDPD. In addition, children, but not adolescents, participating in sports reported higher feelings of social acceptance.
It may be that adolescents have more networks besides a sports club that influence their feelings of social acceptance, while children have a more controlled and limited network and that participating in sports with other children therefore has a greater influence on their feelings of social acceptance. On the other hand, the effect estimate was in favour of the sporting adolescents, and it may be that for these analyses not enough participants were included to show a significant difference. In addition, a study among high school students found a positive association between sports participation and self-belief, that included feelings of social acceptance [51]. Lastly, it may be that children who do not feel accepted withdraw from sport participation. That we did not find significant differences 
between the groups on most of the other self-perception scales, may be due to the fact that our study population scored relatively high on most scales, at least when compared with the 15th and 85th percentile norm values. However, compared to a study sample described by Shapiro and colleagues, the current sample scored lower on the social acceptance, athletic competence and physical appearance scales [52]. That in the current study no associations between sport participation and self-perception concepts were found may be because of other factors than sports participation play a more crucial role in these scales or that different types of sports may have different effects that could not be detected in the current study design.

Finally, despite the fact that the self-efficacy scale was dichotomized which may have led to reduced power, we found a strong association between sports participation and exercise self-efficacy. Self-efficacy is a well-known behavioural determinant of physical activity [53] assuming that exercise self-efficacy influences physical activity. In the current study, we hypothesised another causal pathway, i.e. that sports participation would result in beneficial scores on a range of psychosocial health indicators, including exercise self-efficacy. Sources of influence of self-efficacy are vicarious experiences or modelling and past experiences [46]; therefore, it can be expected that those who participate in sports see others performing sports, and also experience themselves that they are able to perform sports, which both positively impact on their exercise self-efficacy.

An important limitation of the current study is its cross sectional design limiting the conclusions regarding causality. It may as well be that those who experience a better quality of life, or who feel socially accepted and athletically competent, are more likely to participate in organised sports. Therefore, experimental and longitudinal studies are required to study causal or reciprocal relationships. These longitudinal designs would also allow for mediation analyses to study underlying pathways. For instance, in a longitudinal design, we could analyse whether changes in sport participation result in changes in intermediate variables (e.g. self-perception) that in turn result in changes in health-related quality of life. Another limitation is the crude measure of sports participation, which did not include information on duration, quality and type of sports. It may be that team sports have different impact on psychosocial health indicators than individual sports. Furthermore, we did not report whether they participated in regular sports or in adapted forms of sports. The advantage of participation in adapted forms of sports is that children can better focus on their abilities rather than their inabilities [49]. Additionally, the DCGM-37 was in a few cases $(n=9)$ completed by the parent, which may have biased the findings as parents tend to report lower scores than children [37, 54]. However, if this is a systematic bias, it will not affect the association between sport participation and health-related quality of life. Finally, those defined as participating in sports may perform sports at different intensities and frequencies. In conclusion, the group defined as participating in sport is very heterogeneous, and this may have biased the results such that potential associations between sport participation and the outcome may not have been detected. Therefore, future studies should take these aspects into account and may also investigate how the level of sport participation is related to self-perceptions. However, even with the use of this crude measure for sports participation, significant associations with psychosocial health and quality of life were detected.

\section{Conclusions}

Despite some limitations and considering the fact that this is (one of) the first studies addressing this topic in children and adolescents with a CDPD, the current study provides the first indications that participating in sports is beneficial in this population for their psychosocial health. A next step would be to perform experimental and longitudinal studies to see what type of sports, duration and intensities are most promising for improving psychosocial health.

\section{Abbreviations}

ACSM: American College of Sports Medicine; CDPD: Chronic disease or physical disability; DCGM-37: Dutch version of the Disabkids, health-related quality of life questionnaire, 37 items; HAYS: Health in Adapted Youth Sports; S2SF: Sports-2-Stay Fit; SPPA: Self-Perception Profile for Adolescents;

SPPC: Self-Perception Profile for Children

\section{Acknowledgements}

The authors gratefully acknowledge the children and adolescents who participated in the studies.

The Health in Adapted Youth Sports Study (HAYS) study group:

FJG Backx (Department of Rehabilitation, Physical Therapy Science and Sports, Brain Center Rudolf Magnus, University Medical Center Utrecht, Utrecht, The Netherlands), JF de Groot (University of Applied Sciences, Utrecht, The Netherlands), KM Lankhorst (University of Applied Sciences, Utrecht, The Netherlands), TCW Nijboer (Brain Center Rudolf Magnus,

University Medical Center Utrecht, Utrecht, The Netherlands), T Takken (Child Development and Exercise Center, University Medical Center Utrecht, Utrecht, The Netherlands), DW Smits (Brain Center Rudolf Magnus, University Medical Center Utrecht, Utrecht, The Netherlands), OW Verschuren (Brain Center Rudolf Magnus, University Medical Center Utrecht, and De Hoogstraat Rehabilitation, Utrecht, The Netherlands), JMA Visser-Meily (Department of Rehabilitation, Physical Therapy Science and Sports, Brain Center Rudolf Magnus, University Medical Center Utrecht, and De Hoogstraat Rehabilitation, Utrecht, The Netherlands), MJ Volman (Faculty of Social Sciences, Department of General and Special Education, Utrecht University, Utrecht, The Netherlands), HW Wittink (University of Applied Sciences, Utrecht, The Netherlands).

\section{Funding}

The study was funded by an unconditional grant of the Dutch Organization of Health Research (ZONMW) grant number 525001005.

Availability of data and materials

Supporting data is available on request (see corresponding author email). 


\section{Authors' contributions}

StV ran the analyses and drafted the manuscript. KL collected the data and provided intellectual feedback on the manuscript. MZ collected the data and provided intellectual feedback on the manuscript. OV, TT and JdG designed the study and provided intellectual feedback on the manuscript. All authors read and approved the final manuscript.

\section{Ethics approval and consent to participate}

The studies were approved by the Medical Ethics Committee of the University Medical Center Utrecht, the Netherlands. (METC number: 14-332/c and $14-118 / \mathrm{m}$ ). All participants and the parents of participants under 18 years of age provided their informed written consent. Studies were conducted in accordance with the Helsinki Declaration.

\section{Consent for publication}

Not applicable

\section{Competing interests}

Saskia J te Velde, Kristel Lankhorst, Maremka Zwinkels, Olaf Verschuren,

Tim Takken and Janke de Groot have no competing interests.

\section{Publisher's Note}

Springer Nature remains neutral with regard to jurisdictional claims in published maps and institutional affiliations.

\begin{abstract}
Author details
${ }^{1}$ University of Applied Sciences, Utrecht, the Netherlands. ${ }^{2}$ Center of Excellence for Rehabilitation Medicine, Brain Center Rudolf Magnus, University Medical Center Utrecht and De Hoogstraat Rehabilitation, Utrecht, the Netherlands. ${ }^{3}$ Child Development and Exercise Center, University Medical Center Utrecht, Utrecht, the Netherlands. ${ }^{4}$ Netherlands Institute for Health Services Research, Utrecht, The Netherlands.
\end{abstract}

\section{Received: 26 November 2017 Accepted: 27 July 2018}

\section{Published online: 15 August 2018}

\section{References}

1. Warburton DER, Nicol CW, Bredin SSD. Health benefits of physical activity: the evidence. CMAJ. 2006:174:801-9.

2. Kubota Y, Evenson KR, MacLehose RF, Roetker NS, Joshu CE, Folsom AR. Physical activity and lifetime risk of cardiovascular disease and Cancer. Med Sci Sport Exerc. 2017:49:1599-605.

3. Alves AJ, Viana JL, Cavalcante SL, Oliveira NL, Duarte JA, Mota J, et al. Physical activity in primary and secondary prevention of cardiovascular disease: overview updated. World J Cardiol. 2016;8:575-83.

4. Samitz G, Egger M, Zwahlen M. Domains of physical activity and all-cause mortality: systematic review and dose-response meta-analysis of cohort studies. Int J Epidemiol. 2011:40:1382-400.

5. Eime RM, Harvey JT, Brown WJ, Payne WR. Does sports club participation contribute to health-related quality of life? Med Sci Sport Exerc. 2010:42: $1022-8$.

6. Street $\mathrm{G}$, James $\mathrm{R}$, Cutt $\mathrm{H}$. The relationship between organised physical recreation and mental health. Heal Promot J Aust. 2007:18:236-9.

7. Seippel $\varnothing$. The Meanings of Sport: Fun, Health, Beauty or Community? The Meanings of Sport: Fun, Health, Beauty or Community? Sport Soc. 2017;9:51-70

8. Eime RM, Young JA, Harvey JT, Charity MJ, Payne WR. A systematic review of the psychological and social benefits of participation in sport for adults: informing development of a conceptual model of health through sport. Int J Behav Nutr Phys Act. 2013:10:135.

9. Sahlin KB, Lexell J. Impact of organized sports on activity, participation, and quality of life in people with neurologic disabilities. PM R. 2015;7:1081-8.

10. Mitchell TMDF, Barlow CEMS. Review of the role of exercise in improving quality of life in healthy individuals and in those with chronic diseases. Curr Sports Med Rep. 2011;10:211-6.

11. Bullinger M, Schmidt S, Petersen C. Assessing quality of life of children with chronic health conditions and disabilities: a European approach. Int J Rehabil Res. 2002;25:197-206.

12. Crosbie A. The effect of physical training in children with asthma on pulmonary function, aerobic capacity and health-related quality of life: a systematic review of randomized control trials. Pediatr Exerc Sci. 2012;24: $472-89$
13. Kotte EMW, De Groot JF, Winkler AMF, Huijgen BCH, Takken T. Effects of the fitkids exercise therapy program on health-related fitness, walking capacity, and health-related quality of life. Phys Ther. 2014;94:1306-18.

14. Koldoff EA, Holtzclaw BJ. Physical activity among adolescents with cerebral palsy: an integrative review. J. Pediatr. Nurs. 2015;30:e105-17. Elsevier Inc.

15. Kotte EMW, Winkler AMF, Takken T. Fitkids exercise therapy program in the Netherlands. Pediatr Phys Ther. 2013;25:7-13.

16. Neter JE, Schokker DF, de Jong E, Renders CM, Seidell JC, Visscher TLS. The prevalence of overweight and obesity and its determinants in children with and without disabilities. J Pediatr. 2011;158:735-9.

17. Carlon SL, Taylor NF, Dodd K, Shields N. Differences in habitual physical activity levels of young people with cerebral palsy and their typically developing peers: a systematic review. Disabil Rehabil. 2013;35:647-55.

18. Dahan-Oliel N, Shikako-Thomas K, Majnemer A. Quality of life and leisure participation in children with neurodevelopmental disabilities: a thematic analysis of the literature. Qual Life Res. 2012;21:427-39.

19. Rimmer JA, Rowland JL, Rimmer JA, Rowland JL. Physical activity for youth with disabilities: a critical need in an underserved population. Dev Neurorehabil. 2008:11:141-8.

20. Buffart LM, Roebroeck ME, Rol M, Stam HJ, Van Den Berg-Emons RJG. Netherlands transition research group south-west. Triad of physical activity, aerobic fitness and obesity in adolescents and young adults with myelomeningocele. J Rehabil Med. 2008:40:70-5.

21. Rimmer JH, Riley B, Wang E, Rauworth A, Jurkowski J. Physical Activity Participation Among Persons with Disabilities. Am. J. Prev. Med. Introd. 2004;26:419-25.

22. Sawin KJ, Bellin MH. Quality of life in individuals with spina bifida: a research update. Dev Disabil Res Rev. 2010;16:47-59.

23. Ferguson MK, Kovacs AH. Quality of life in children and young adults with cardiac conditions. Curr Opin Cardiol. 2013;28:115-21.

24. Houben-van Herten M, Bai G, Hafkamp E, Landgraf JM, Raat H. Determinants of health-related quality of life in school-aged children: a general population study in the Netherlands. PLoS One. 2015;10:1-13.

25. Dinomais M, Gambart G, Bruneau A, Bontoux L, Deries $X$, Tessiot C, et al. Social functioning and self-esteem in young people with disabilities participating in adapted competitive sport. Neuropediatrics. 2010;41:49-54.

26. Abdou Y, Erpelding OM. Contribution of taking part in sport to the association between physical activity and quality of life. Qual Life Res. 2013;22:2021-9.

27. Drakouli M, Petsios K, Giannakopoulou M, Patiraki E, Matziou V, et al. Determinants of quality of life in children and adolescents with CHD: a systematic review. Cardiol. Young. 2015;25:1027-36.

28. Balaguer I, Atienza-Gonzalez FL, Duda JL. Self-perceptions, self-worth and sport participation in adolescents. Span J Psychol. 2012;15:624-30.

29. Babic MJ, Morgan PJ, Plotnikoff RC, Lonsdale C, White RL, Lubans DR. Physical activity and physical self-concept in youth: systematic review and meta-analysis. Sport Med. 2014;44:1589-601.

30. Hausenblas HA, Fallon EA. Exercise and body image: a meta-analysis. Psychol Health. 2006;21:33-47.

31. Lankhorst $K$, van der Ende-Kastelijn $K$, de Groot J, Zwinkels M, Verschuren $O$, Backx F, et al. Health in Adapted Youth Sports Study (HAYS): health effects of sports participation in children and adolescents with a chronic disease or physical disability. Springerplus. 2015;4:796. Springer International Publishing

32. Zwinkels $\mathrm{M}$, Verschuren $\mathrm{O}$, Lankhorst $\mathrm{K}$, van der Ende-Kastelijn $\mathrm{K}$, de Groot J, Backx F, et al. Sport-2-Stay-Fit study: Health effects of after-school sport participation in children and adolescents with a chronic disease or physical disability. BMC Sports Sci. Med. Rehabil. 2015;7:22.

33. de Hollander EL, Milder I, Proper K. Beweeg- en sportgedrag van mensen met een chronische aandoening of lichamelijke beperking. Rijksinstituut voor Volksgezondheid en Milieu. Bilthoven; 2015.

34. Kemper HCG, Ooijendijk WT, Stiggelbout M. Consensus over de Nederlandse norm voor gezond bewegen (consensus about the Dutch norm for physical activity). Tijdschr voor Sport Geneeskd. 2000;78:180-3.

35. Van Brussel M, Van Der Net J, Hulzebos E, Helders PJM, Takken T. The Utrecht approach to exercise in chronic childhood conditions: the decade in review. Pediatr Phys Ther. 2011;

36. Verschuren $\mathrm{O}$, Peterson MD, Balemans ACJ, Hurvitz EA. Exercise and physical activity recommendations for people with cerebral palsy. Dev. Med. Child Neurol. 2016;58:798-808.

37. Mueller-Godeffroy E, Thyen U, Bullinger M. Health-related quality of life in children and adolescents with cerebral palsy: a secondary analysis of the DISABKIDS questionnaire in the field-study cerebral palsy subgroup. Neuropediatrics. 2016;47:97-106. 
38. Froisland DH, Markestad T, Wentzel-Larsen T, Skrivarhaug T, Dahl-Jorgensen K, Graue M. Reliability and validity of the Norwegian child and parent versions of the DISABKIDS Chronic Generic Module (DCGM-37) and Diabetes-Specific Module (DSM-10). Health Qual. Life Outcomes. 2012;10:19. BioMed Central Ltd

39. Simeoni MC, Schmidt S, Muehlan H, Debensason D, Bullinger M, Petersen C, et al. Field testing of a European quality of life instrument for children and adolescents with chronic conditions: the 37-item DISABKIDS chronic generic module. Qual Life Res. 2007;16:881-93.

40. Harter S. The self-perception profile for children: revision of the perceived competence scale for children. Manual. Denver, CO: University of Denver; 1985.

41. Veerman JWE, Treffers DA, Van der Bergh BRH, Ten Brink LT Competentiebelevingsschaal voor kinderen. Amsterdam: Harcourt Test Publishers; 2004

42. Veerman JW, Ten Brink LT. Veerman measuring childrens self-concept factorial validity. J Pers Assess. 1996;67:142-54.

43. Treffers, Goedhardt AW, Veerman JW, Van den bergh BRH, Ackaert L, de Rycke L. Handleiding Competentie Belevingsschaal voor Adolescenten. Lisse: Swets Test Publishers; 2002.

44. Nooijen CFJ, Post MWM, Spijkerman DCM, Bergen MP, Stam HJ, Van Den Berg-Emons RJG. Exercise self-efficacy in persons with spinal cord injury: psychometric properties of the Dutch translation of the exercise self-efficacy scale. J Rehabil Med. 2013:45:347-50.

45. Kroll T, Kehn M, Ho P-S, Groah S. The SCl exercise self-efficacy scale (ESES): development and psychometric properties. Int J Behav Nutr Phys Act. 2007:4:34.

46. Bandura A. Health promotion from the perspective of social cognitive theory; 2012. p. 37-41.

47. Bandura A. Self-efficacy. The exercise of control. New York: Freeman; 1997.

48. Durstine $L$, Moore GE, Painter P, Roberts SO. ACSM's exercise management for persons with chronic diseases and disabilities. 3rd ed. Champaign: Humen Kinetics; 2009.

49. Yazicioglu K, Yavuz F, Goktepe AS, Tan AK. Influence of adapted sports on quality of life and life satisfaction in sport participants and non-sport participants with physical disabilities. Disabil. Health J. 2012;5:249-53.

50. Groff DG, Lundberg NR, Zabriskie RB. Influence of adapted sport on quality of life: perceptions of athletes with cerebral palsy. Disabil Rehabil. 2009;31: 318-26.

51. Dodge T, Lambert ÆSFF. Positive self-beliefs as a mediator of the relationship between adolescents' sports participation and health in young adulthood. J Youth Adolesc. 2009;38:813-25.

52. Shapiro DR, Martin JJ. The relationships among sport self-perceptions and social well-being in athletes with physical disabilities. Disabil Health J Elsevier Inc. 2014;7:42-8.

53. Plotnikoff RC, Costigan SA, Karunamuni N, Lubans DR. Social cognitive theories used to explain physical activity behavior in adolescents: a systematic review and meta-analysis. Prev Med. 2013:56:245-53.

54. Baca CB, Vickrey BG, Hays RD, Vassar SD, Berg AT. Differences in child versus parent reports of the child's health-related quality of life in children with epilepsy and healthy siblings. Value Heal. 2010;13:778-86. International Society for Pharmacoeconomics and Outcomes Research (ISPOR)

\section{Submit your manuscript to a SpringerOpen ${ }^{\circ}$ journal and benefit from:}

- Convenient online submission

- Rigorous peer review

Open access: articles freely available online

- High visibility within the field

Retaining the copyright to your article

Submit your next manuscript at $\boldsymbol{\nabla}$ springeropen.com 